\title{
Bases epistemológicas sobre sentido(s) e significado(s) do trabalho em estudos nacionais
}

Epistemological bases for senses and meanings of work in Brazilian studies Bases epistemológicas de los sentido(s) y significado(s) del trabajo en los estudios nacionales

\author{
Lucas SCHWEITZER ${ }^{1}$ \\ Júlia GONÇALVES \\ Suzana da Rosa TOLFO \\ Narbal SILVA \\ Universidade Federal de Santa Catarina, Florianopólis, SC, Brasil
}

ResumO As profundas mudanças no contexto de trabalho e sua centralidade sociológica e psicológica indicam a importância de entender os sentidos e significados atribuídos a ele. Neste artigo, o objetivo é analisar os fundamentos epistemológicos que sustentam as produções científicas nacionais em estudos empíricos sobre o fenômeno. Para tanto, realizou-se uma revisão integrativa, por meio de 25 artigos indexados nas bases de dados PePSIC e SciELO. Constata-se o amplo desenvolvimento da produção científica, com a prevalência de estudos que utilizam a abordagem existencialista e a sócio-histórica, bem como os aportes da psicodinâmica do trabalho concomitante às demais. As perspectivas epistemológicas predominantes nessa produção localizam-se nos quadrantes subjetivos interpretativista e humanista radical e, inseridos no eixo da subjetividade em Psicologia do Trabalho e das Organizações. A diversidade de abordagens sobre o fenômeno remete à importância de uma maior compreensão teórica, evitando-se incongruências na construção de pesquisas, e também a ampliação do escopo do estudo com a inclusão de análises internacionais.

Palavras-chave:

Sentido e significado; trabalho; epistemologia.

\section{Abstract}

The profound changes in the context of work and its sociological and psychological centrality indicate the relevance of understanding the senses and meanings attributed to it. The objective of this study is to analyze the epistemological foundations that sustain Brazilian scientific production in empirical studies that deal with the phenomenon. An integrative review was done with 25 publications indexed on the PePSIC and SciELO databases. It is noteworthy that the scientific production is in full development, with a prevalence of studies using the existentialist and socio-historical approaches, as well as the increasing use of the psychodynamic of work approach, in collaboration with the others. Epistemological perspectives are, mainly, located in two subjective quadrants, and the subjectivity axis of Work and Organizational Psychology. The diversity of approaches to the phenomenon underscores the importance of greater theoretical understanding, avoiding inconsistencies in the construction of research, as well as expanding the scope of the study with the inclusion of international analysis. Keywords:

Sense and meaning; work; epistemology.

\section{Resumen}

Los profundos cambios en el contexto del trabajo y su centralidad sociológica y psicológica indican

la relevancia de compreender los sentidos y significados atribuidos al mismo. En este artículo, el objetivo es analizar los fundamentos epistemológicos que sustentan las producciones científicas nacionales en estudios empíricos que versan sobre el fenómeno. Para ello, se realizó una revisión integradora de 25 artículos indexados en las bases de datos PePSIC y SciELO. Se resalta que la producción científica se encuentra en amplio desarrollo, con la prevalência de estúdios com base existencialista o socio-histórica, así como los aportes de la 
vertiente psicodinámica del trabajo en concomitancia con las demás. Las perspectivas epistemológicas de estar producción se encuentran principalmente asociadas a los cuadrantes subjetivo interpretativo y humanista radical, e inseridos en el eje de la subjetividad en Psicología del Trabajo y de las Organizaciones. La diversidad de abordajes sobre el fenómeno evidencia la importancia de una mayor compresión teórica, evitándose incongruencias en la realización de investigaciones, y también la ampliación del alcance del estudio con la inclusión de análisis internacionales.

Palabras-clave:

Sentido y significado; trabajo, epistemología.

$\mathrm{N}$

as duas últimas décadas o contexto do trabalho passou por alterações de diversas ordens, relacionadas a condições econômicas, sociopolíticas, demográficas e tecnológicas, entre outras. Tais alterações incluem fenômenos como a globalização, o aumento da competitividade entre países e organizações, a reestruturação produtiva, as inovações socio-organizacionais e a flexibilização das relações de trabalho (Borges \& Yamamoto, 2014; Tolfo \& Piccinini, 2007).

Esse contexto suscita discussões polarizadas por estudiosos da área das organizações e do trabalho, principalmente quanto à centralidade da categoria trabalho na vida das pessoas. De um lado estão perspectivas que afirmam a perda da centralidade da categoria trabalho e consideram-no menos central para as pessoas atualmente que em outros períodos (Bauman, 2001; Offe, 1989). Em oposição a essa perspectiva está a defesa do trabalho como categoria central, o principal fato social, relacionado com a construção da identidade e a processos de socialização (Antunes, 2003; Luna, 2005; Zanelli, 2010). Ao se adotar a perspectiva da centralidade do trabalho, pressupõe-se sua relação com os comportamentos e construtos ligados ao trabalho e ao sujeito, entendendo esta centralidade como o componente mais importante sobre o fenômeno sentido(s) e significado(s) do trabalho, quando consideradas as principais perspectivas teóricas voltadas a abordá-lo. A importância de compreender esse fenômeno psicológico em sua complexidade, a partir de diferentes perspectivas teóricas e em sua historicidade é, então, reiterada (Antunes, 2003).

O uso dos termos sentido ou significado não denota consenso entre autores nos estudos, porém, etimologicamente ambos surgem do termo latino sensos, que se refere à percepção, significado ou interpretação, sentimento e empreendimento (Harper, 2005 citado por Tolfo, 2015). Ao se reportar aos dicionários, o termo sentido remete a significado, e vice-versa, ambos relacionados à percepção, sentimento e cognição (Tolfo, 2015). A busca por definições precisas dos termos remete a que os significados são construídos e apropriados coletivamente em determinado contexto, enquanto os sentidos se referem a uma produção pessoal a partir da apreensão individual de tais significados e estes são conceitos interdependentes (Tolfo, Coutinho, Baasch, \& Cugnier, 2011). Esta necessidade de definição decorre da constatação que, ora os termos são tratados como sinônimos, ora como fenômenos diferentes, dificultando a evolução de estudos sobre a temática (Tolfo \& Piccinini, 2007).

Ao se considerar as bases históricas do fenômeno, é creditado a Morse e Weiss (1955) o desenvolvimento dos primeiros estudos acerca do significado do trabalho nos Estados Unidos (Goulart, 2009). Nesta pesquisa, o questionamento foi se as pessoas continuariam trabalhando ao ganhar na loteria, e prevaleceram respostas positivas, principalmente para sujeitos entre 25 e 30 anos. Na década de 1960, Tausky e Piedmond (1968) pesquisaram o significado do trabalho para trabalhadores manuais e as respostas dos sujeitos relacionaram-no ao próprio salário, ao pertencimento e à aceitação social (Tolfo, 2015).

Também é um marco histórico no estudo do significado do trabalho a abordagem sobre qualidade de vida no emprego, sendo o sentido do exercício incluído por Hackman e Oldhan (1975) como um dos seus componentes (Tolfo \& Piccinini, 2007). Porém, as pesquisas que se destacam como marco histórico fundamental dos estudos sobre significados do trabalho foram realizadas pelo grupo Meaning of Work International Research Team (MOW, 1987) e trouxeram contribuições em nível mundial para o entendimento do fenômeno. O grupo definiu o construto como sendo multidimensional e dinâmico, formado pela interação entre variáveis pessoais e ambientais e influenciado pelas mudanças no ser humano, ao seu redor ou no próprio trabalho (Bendassolli, 2009).

Existem ainda outras diferentes bases que conceituam significados e sentidos do trabalho na psicologia, mostrando a relevância social e cientifica de compreender o tema e de analisá-lo à luz das bases epistemológicas, bem como identificar como a temática vem sendo abordada em publicações de periódicos científicos disponíveis em bases de dados nacionais. Para tanto, este estudo teve o objetivo de analisar os fundamentos 
teóricos e epistemológicos que sustentam as produções científicas nacionais em estudos empíricos sobre o fenômeno em questão na psicologia. No que se refere à discussão sobre os aspectos epistemológicos, parte-se dos paradigmas sociológicos de Burrell e Morgan (1979) e dos três eixos temáticos propostos por Bendassolli, Borges-Andrade e Malvezzi (2010), que compõem e classificam os estudos na área da Psicologia do Trabalho e das Organizações (PTO) no Brasil, para proceder as articulações teóricas com os estudos sobre sentido(s) e significado(s) do trabalho.

Os quatro paradigmas elaborados por Burrel e Morgan (1979) auxiliam a compreensão das divergências e aproximações existentes nos pressupostos teóricos e epistemológicos que circunscrevem os fenômenos de pesquisa, em especial, os de natureza psicossocial, com uma proposta que relaciona as teorias da organização com contextos sociológicos mais amplos. Esses paradigmas englobam duas dimensões: a objetiva, que compreende os paradigmas funcionalista e estruturalista radical; e a subjetiva, que contempla os paradigmas interpretativista e o humanista radical. Baseados nesses pressupostos e nas diversas perspectivas explicitadas para o estudo dos sentidos e significados do trabalho, é possível identificar as aproximações entre os paradigmas propostos pelos autores e as teorias utilizadas nos artigos analisados ${ }^{2}$.

Outra maneira de compreender as perspectivas epistemológicas utilizadas em artigos, especificamente em PTO, é proposta por Bendassolli et al. (2010). Esses autores pressupõem três eixos temáticos da PTO: o do comportamento, o da subjetividade e o clínico, a partir de quatro paradigmas propostos por Guba (1990): o positivista, o pós-positivista, o crítico e o clínico.

Este artigo torna-se relevante, pois apesar de uma significativa quantidade de produções científicas de base empírica sobre o assunto nas últimas décadas e de alguns poucos estudos teóricos também nacionais, que identificam os conceitos sobre sentidos e significados do trabalho subjacentes a diferentes perspectivas na psicologia (Tolfo et al, 2011; Tolfo \& Piccinini, 2007), não se encontrou na revisão da literatura discussões aprofundadas sobre aspectos de ordem epistemológica do fenômeno. Os resultados apresentados avançam em relação às revisões já realizadas, seu caráter de ineditismo está em contemplar estudos empíricos e a análise dos mesmos com base nas perspectivas epistemológicas que os sustentam. Este estudo objetiva preencher esta lacuna, uma vez que conhecer os pressupostos presentes nas bases do conhecimento científico é fundamental para que um cientista alcance os objetivos em um empreendimento de investigação.

A identificação de padrões de produção científica, bem como o mapeamento de perspectivas metodológicas e temáticas abordadas, ajuda a definir lacunas e promover avanços em determinados campos de pesquisa (Santos \& Kobashi, 2009). Além disso, pesquisar implica em fazer ciência com conhecimento de causa quanto às decisões e articulações entre a epistemologia, a ontologia, a concepção de natureza humana e de sujeito, e tomar decisões sobre os procedimentos coerentes com o método escolhido. Na seção que segue, conforme os objetivos propostos, serão demostrados os procedimentos metodológicos adotados à realização do estudo.

\section{MÉTODO}

Esta pesquisa configurou-se como uma revisão do conhecimento científico acerca do fenômeno abordado e sobre suas bases epistemológicas, de cunho documental, contemplando o publicado em periódicos indexados nas bases de dados bibliográficas SciELO e PePSIC. A escolha destas fontes de pesquisa ocorreu porque essas bibliotecas eletrônicas são uma forma de garantir a visibilidade e a acessibilidade da literatura científica atualizada, estão entre as que mais publicam artigos em psicologia, além de sistematizar e demonstrar, inicialmente, a produção nacional disponível na internet. A revisão integrativa, como procedimento escolhido, ocorreu dada a exigência de estruturação e confiabilidade dos dados adquiridos. Com este procedimento, acredita-se ser possível revisar, criticar e sistematizar a literatura representativa de uma forma integrada (Torraco, 2005).

A revisão, operacionalizada por meio da busca eletrônica de artigos indexados nas bases citadas, foi feita a partir dos seguintes descritores, previamente selecionados: sentido do trabalho, sentidos do trabalho, significado do trabalho e significados do trabalho, estes foram separadamente inseridos em Índices de assuntos. O período de tempo definido para observar a produção existente foi de 2005 a 2015, finalizando com as publicações realizadas até o dia 30 de maio de 2015. A delimitação do período deveu-se ao início de uma agenda de pesquisa de alguns autores (Tolfo, Coutinho, Almeida, Baasch, \& Cugnier, 2005; Tolfo et al., 2011; Tolfo \& Piccinini, 
2007) que buscaram trazer maior clareza na definição do fenômeno aqui estudado, ao procurar identificá-lo à luz de diferentes abordagens teóricas na psicologia.

Os seguintes critérios foram adotados para a rejeição dos artigos, considerando o objetivo proposto: (a) artigos que não eram disponíveis na íntegra; (b) teses, dissertações, projetos e áudios; (c) artigos publicados fora do período selecionado; (d) artigos de revisões teóricas ou análise documental e (e) artigos que não atendessem ao objetivo deste trabalho (por exemplo, relatos de experiências de estágios, pesquisa-ação sem intervenções claras e artigos que não abordassem especificamente o construto analisado).

Com base nestes critérios, encontrou-se inicialmente 21 publicações no indexador SciELO, utilizando os quatro descritores mencionados, e 16 publicações no indexador PePSIC, totalizando 37 publicações. Destas publicações, utilizando os critérios de exclusão e comparando nas bases de dados para verificar publicações repetidas, restaram 27 artigos. Após leitura e análise atenta e na íntegra dos artigos selecionados, identificou-se que dois deles não se referiam ao propósito desta pesquisa (pesquisa-ação sem percurso metodológico claro para a análise e sem abordar o construto especifico objeto desta pesquisa). Foram, então, selecionados 25 artigos para a descrição e discussão.

Para a análise dos 25 artigos selecionados criou-se um quadro com as informações relevantes dos estudos, e emergiram três grandes categorias de análise. A primeira categoria foi a das características da produção científica, e foram identificadas as palavras de busca, ano de publicação, população pesquisada, método e procedimentos de pesquisa e os principais resultados encontrados. Outra categoria identificada refere-se à produção científica a partir das perspectivas epistemológicas na psicologia, definindo-as e abordando os principais conceitos adotados nos artigos. Por fim, propõe-se a associação das perspectivas epistemológicas na psicologia aos paradigmas sociológicos segundo Burrell e Morgan (1979) e aos três temas-chaves/eixos propostos por Bendassolli et al. (2010), e se apresentam as aproximações possíveis. Considerando os procedimentos utilizados à realização do estudo, na seção que segue se fará a apresentação e discussão dos resultados, a partir de categorias temáticas estruturadas com base nas descobertas feitas por meio das leituras integrais dos artigos selecionados.

\section{RESULTADOS}

\section{Caracterização dos estudos empíricos sobre sentido(s) e significado(s) do trabalho}

A análise dos estudos empíricos publicados nas bases de dados nacionais pesquisadas acerca do(s) sentido(s) e significado(s) do trabalho, permite identificar a prevalência de publicações na segunda metade do período selecionado para a busca, entre 2010 e 2015. Nos primeiros cinco anos da década foram identificadas as publicações de oito artigos, enquanto nos cinco anos finais, encontraram-se 17 artigos. Constata-se, portanto, um aumento expressivo de publicações sobre o tema, o que demonstra o interesse crescente de pesquisadores brasileiros no estudo da temática e na busca por uma delimitação do campo de estudo e divulgação de suas produções em periódicos nacionais. O crescente número de publicações também parece indicar que o assunto ainda é recente no meio científico, com estudos mais sistemáticos pelos psicólogos somente a partir da década de 1970 (Tolfo et al., 2011) e estudos empíricos no final da década seguinte (MOW, 1987).

A maior parte dos estudos identificados trata de sujeitos inseridos em organizações formais de trabalho, o que corrobora o fato de que, historicamente, a psicologia tem se dedicado ao estudo do trabalho sob a forma de assalariamento, ou seja, do emprego, na média e grande empresa (Sato, 2011). Apesar disso, é possível identificar uma tendência para investigar trabalhadores informais ou inseridos em organizações com modelos alternativos de gestão, tais como cooperativas, empreendimentos solidários, entre outros. Esse fato indica que os autores não estão dedicados exclusivamente ao mercado formal de trabalho e que a pesquisa sobre o assunto se articula com as alterações no mundo do trabalho.

A análise permite constatar a prevalência de estudos com uso de métodos qualitativos $(n=19)$, quatro estudos com métodos quantitativos e dois com o uso de métodos mistos. A maior parte das investigações analisadas foi encontrada por meio da busca pelo descritor sentidos do trabalho, com 14 artigos identificados, enquanto com a busca por significado do trabalho foram encontrados seis artigos. Os termos sentido do trabalho e significados do trabalho suscitam menor quantidade de estudos, com três e dois artigos respectivamente. Tais dados demonstram a forma como os pesquisadores têm se referido ao fenômeno e remetem ao próprio método utilizado, visto que todos os estudos encontrados com os termos sentidos do trabalho ou sentido do trabalho 
utilizam procedimentos qualitativos. Cabe destacar que todos os estudos quantitativos fizeram uso do termo significado do trabalho para se referir ao construto estudado.

Apesar dos conceitos de significado e sentido serem frequentemente tratados como sinônimos na literatura e no âmbito acadêmico (Tolfo \& Piccinini, 2007), a maior parte dos artigos identificados apresenta diferenciações teóricas entre os conceitos. É possível, também, relacionar os termos e os métodos utilizados pelos autores com a coerência epistemológica dos estudos, visto que, entendendo os significados como construções coletivas em determinado momento histórico, econômico e social, e os sentidos como uma produção pessoal a partir da apreensão individual dos significados coletivos (Tolfo et al., 2011), o primeiro passa a ser mais acessado por meio de métodos quantitativos e o segundo com os métodos qualitativos, ainda que tais conceitos sejam interdependentes. Outra possibilidade a ser considerada é a influência dos estudos do grupo MOW, que utiliza o termo significados, privilegia a identificação de variáveis e o método quantitativo para comparar a atribuição de significados em diferentes países.

Nos estudos de abordagem qualitativa, a estratégia de coleta de informações mais utilizada foi a entrevista semiestruturada. Em algumas delas, identificou-se a opção por entrevistas junto a observações e grupos focais. Para a verificação dos dados obtidos, os principais procedimentos utilizados foram análise de conteúdo, de informações ou de discursos. O foco de análise foi nas informações trazidas pelos sujeitos e nos sentidos que os mesmos atribuem ao seu trabalho, adequando-se aos pressupostos da própria pesquisa qualitativa, em que alguns casos são estudados e analisados extensivamente em sua complexidade, por vezes visando captar o significado subjetivo das questões a partir da perspectiva dos participantes (Flick, 2013).

Nos estudos quantitativos, a coleta de dados foi realizada por meio de questionários, escalas ou inventários, caracterizando investigações baseadas em levantamentos com grande número de sujeitos (entre 230 e 7425 indivíduos), com uso de recursos estatísticos para a análise dos dados. Já nos estudos com métodos mistos foram utilizados escalas e questionários para a coleta quantitativa, associados a entrevistas semiestruturadas, neste caso, trabalhando com um número menor de sujeitos (menos de cem pessoas). Tal dado pode estar relacionado com a complexidade dos métodos mistos, em que são combinados dados qualitativos, que envolvem textos, discursos, verbalizações e documentos, e dados quantitativos, com ênfase na utilização de números (Creswell, 2010). A seção que segue refere-se à análise da produção científica a partir das perspectivas epistemológicas baseadas na Psicologia.

\section{Produção científica sobre sentido(s) e significado(s) e perspectivas epistemológicas na psico-} logia

Há diversas perspectivas teóricas e epistemológicas adotadas para discutir o fenômeno sentido(s) e significado(s) do trabalho. Dentre as diferentes correntes epistemológicas que dão suporte aos estudos sobre o tema na psicologia, é possível identificar quatro perspectivas principais (Tolfo, 2015): (a) sócio-histórica ou histórico-crítica (ou ainda histórico-cultural), cujos principais autores são Alexei N. Leontiev e Lev Vygotsky; (b) cognitivista, a partir do referencial do Meaning of Work International Research Team (MOW) e da autora brasileira Lívia Borges; (c) humanista-fenomenológica ou existencialista, com os estudos de Estelle Morin e; (d) construcionista, cujos representantes são Peter L. Berger, Thomas Luckman e Mary Jane Spink e colaboradores. Apesar de estas perspectivas serem bastante consolidadas e difundidas, é possível identificar, a partir da revisão de literatura sobre as abordagens teóricas nos estudos, outra corrente epistemológica: (e) psicodinâmica do trabalho, cujo precursor foi Jacques Christophe Dejours. Dessa forma, a seguir são descritos os principais pressupostos destas abordagens.

\section{Perspectiva cognitivista}

Um dos principais precursores dos estudos sobre significado do trabalho, o grupo de investigação MOW (1987), na década de 1980, dedicou-se à condução de pesquisas com amostras representativas, com vistas a definir e identificar variáveis que expliquem os significados atribuídos ao trabalho em diferentes países. Atribui-se a esse grupo as mais extensas contribuições para a compreensão do fenômeno significado do trabalho em nível mundial (Tolfo, 2015).

A equipe do grupo MOW conceituou o significado do trabalho como um construto psicológico multidimensional e dinâmico, formado da interação entre variáveis pessoais e ambientais e, influenciado pelas mudanças no ser humano, ao seu redor ou no trabalho (Ruiz-Quintanilla \& Claes, 2000; Tolfo, 2015). Para 
eles, o significado do trabalho é uma cognição social que envolve aspectos históricos, econômicos, políticos e culturais (Bendassolli \& Guedes, 2014). Esses pesquisadores estruturaram os dados de pesquisas em três dimensões: a centralidade do trabalho (relacionada à identificação pessoal com o trabalho, ao seu valor e importância em relação às outras esferas da vida), as normas sociais sobre o trabalho (crenças e expectativas sobre direitos e deveres no trabalho) e os resultados valorizados do trabalho/metas do trabalho (razões para trabalhar e o que se objetiva ao trabalhar) (Ruiz-Quintanilla \& Claes, 2000). Desde então, estudos foram conduzidos e instrumentos de medida adaptados e validados para a realidade brasileira utilizando destes conceitos.

A pesquisadora Lívia Borges $(1997,1998)$ torna-se referência nos estudos brasileiros desta perspectiva $\mathrm{e}$, motivada por algumas inadequações referentes às peculiaridades da realidade brasileira, elaborou o IST (Inventário do Significado do Trabalho), o qual se mostrou apropriado para as reflexões sobre o significado do trabalho em nível nacional. A autora aprofundou a análise sobre a estrutura fatorial das crenças sobre o trabalho a partir da diferenciação entre atributos valorativos (como o trabalho deve ser, às exigências sociais, à justiça no trabalho, ao esforço corporal e à desumanização, à realização pessoal e à sobrevivência pessoal e familiar) e descritivos (como o trabalho realmente é, o êxito e a realização pessoal, a justiça no trabalho, a sobrevivência pessoal e familiar, a independência econômica e a carga mental) (Borges, 1998).

Das pesquisas analisadas neste estudo, pode-se identificar a adoção da perspectiva cognitivista em quatro artigos (Bendassolli, Alves, \& Torres, 2014; Cavazotte, Lemos, \& Viana, 2012; Kubo \& Gouvêa, 2012; Silva, Kemp, Carvalho-Freitas, \& Brighenti, 2015). Dentre eles, destaca-se o artigo de Bendassolli et al. (2014), que objetivou validar um inventário de significado do trabalho por meio de um estudo quantitativo com 230 profissionais de indústrias criativas do Rio Grande do Norte. Neste estudo foi utilizado o modelo do grupo MOW, cujo conceito de significado do trabalho foi composto pelas três dimensões descritas pelo grupo (centralidade do trabalho, normas societais e os resultados valorizados de trabalho e metas laborais).

No estudo de abordagem mista, Silva et al. (2015) identificaram o significado atribuído ao trabalho voluntário para 67 participantes de um programa de voluntariado corporativo de empresa multinacional italiana de autopeças e utilizaram o conceito de significado do trabalho proposto por Lívia Borges. Para estes autores, trata-se de uma cognição subjetiva e social, que apresenta componentes subjetivos e aspectos socialmente compartilhados e associados a condições sócio-históricas, com base nas categorias do modelo: centralidade do trabalho, atributos valorativos, atributos descritivos e hierarquia de atributos (Silva et al., 2015).

\section{Perspectiva existencialista}

Os estudos do grupo MOW e a abordagem existencialista de Victor Frankl são a base dos estudos de Estelle Morin e seus colaboradores, classificados como humanistas-fenomenológicos (Bendassolli, 2009) ou existencialistas (Morin, Tonelli, \& Pliopas, 2007; Tolfo et al., 2011). Para Morin (2001), são cinco as principais razões que levam as pessoas a trabalharem: realizar-se e atualizar suas competências e potencialidades; adquirir segurança e ser autônomo; relacionar-se com os outros e estar vinculado a grupos; prestar serviço à sociedade; e dar sentido a vida, incluindo fazer e manter-se ocupado.

Conforme os pressupostos desta perspectiva, dar sentido aos próprios atos é uma necessidade vital para o ser humano, que busca dar a suas condutas um sentido aceitável para si e para sociedade em que vive. O sentido do trabalho se apresenta, então, como um efeito, um produto da atividade humana e pode ser descrito com base em três componentes: a significação do trabalho (representações que o sujeito tem de sua atividade e o valor que lhe atribui), a orientação do sujeito ao trabalho (inclinação para o trabalho, o que busca e o que guia suas ações) e a coerência que o trabalho tem para o sujeito, ou seja, o equilíbrio que ele espera de sua relação com o trabalho (Morin, 2001).

Nos artigos analisados identificaram-se seis estudos (Bendassolli \& Borges-Andrade, 2011; Bendassolli \& Borges-Andrade, 2015; Bitencourt, Onuma, Piccinini, Moreira, \& Severo, 2014; Morin, Tonelli, \& Pliopas, 2007; Padilha \& Grande, 2011; Toledo, Kemp, \& Machado, 2014) que se apropriam dessa abordagem para coleta e análise de dados, o que corrobora com a afirmação de Bendassolli (2009) desta como uma das perspectivas emergentes de investigação dos sentidos do trabalho. Dentre esses estudos, Bitencourt et al. (2014) objetivaram compreender os sentidos do trabalho para jovens trainees de uma grande empresa e para jovens trabalhadores de um empreendimento solidário. Os autores constataram que o sentido do trabalho foi relacionado a aspectos como: classe social, grau de escolaridade, tipo de contrato de trabalho, aprendizagem e realização, bem como valores morais. Os resultados do estudo de Bendassolli e Borges-Andrade (2011), também 
na perspectiva existencialista, com 451 profissionais de indústrias criativas do estado de São Paulo, demostrou que os fatores mais associados a um trabalho com significado são: possibilidade de aprender e se desenvolver, sua utilidade social, oportunidade de identificação e de expressão, autonomia, boas relações interpessoais e respeito às questões éticas (Bendassolli \& Borges-Andrade, 2011).

Outros estudos se utilizaram dos conceitos propostos por Estelle Morin em convergência com outros autores e/ou perspectivas epistemológicas (Baasch \& Laner, 2011; Coutinho, Diogo, \& Joaquim, 2008; Mendes \& Santos, 2013; Souza \& Moulin, 2014). O estudo de Coutinho et al. (2008) adotou a perspectiva existencialista em convergência com outra abordagem - psicodinâmica do trabalho. Embora sejam abordados diferentes autores, o sentido do trabalho é compreendido como uma produção singular de cada sujeito relacionado com o processo coletivo de significação. Já Mendes e Santos (2013) privilegiam a perspectiva existencialista, mas contemplam autores da psicodinâmica do trabalho e da perspectiva construcionista social e asseveram que tanto os sentidos quanto os significados provêm de um mesmo contexto, vinculando os sentidos aos anseios individuais, e os significados às exigências e peculiaridades da função ou da organização. Nessa perspectiva, os sentidos no trabalho são relacionados aos anseios do trabalhador sobre a ação executada (autorrealização, satisfação, liberdade, reconhecimento), que o autorizam a dizer sobre os benefícios (ou malefícios) da função ou ação para si mesmo (Mendes \& Santos, 2013).

\section{Perspectiva sócio-histórica}

A perspectiva sócio-histórica foi bastante recorrente dentre os estudos analisados. Nesta abordagem, compreende-se que o "mundo psicológico" dos seres humanos é construído por meio do registro das experiências vivenciadas na relação com o ambiente sociocultural. O homem, ao mesmo tempo em que atua no mundo, modifica a realidade e a si mesmo, sendo assim os significados sociais, generalizados e mediadores do processo de comunicação, são produções históricas e sociais, relativamente estáveis e compartilhadas (Aguiar, Liebesny, Marchesan, \& Sanchez, 2009). Os significados sociais, que serão internalizados e transformados em sentidos, só existem porque os homens os constituíram e os constituem permanentemente. No que se refere ao sentido não há apenas reprodução do já criado, mas a sua constituição com base na dialética interna/subjetiva, ou seja, são respostas históricas e singulares ao mesmo tempo, não são superficiais, imediatas. Constituem-se a partir de complexas reorganizações e arranjos em que a vivência cognitiva e afetiva é acionada e mobilizada (Aguiar et al., 2009).

Essa perspectiva privilegia a categoria sentido, pois esse conceito remete a uma compreensão singular do sujeito, mais dinâmica e variante do que significado. Assim, os significados são produções históricas e sociais que adquirem, no âmbito do ser humano, um sentido pessoal, relacionado com a realidade, com a própria vida e com motivos individuais. Os significados são sentidos compartilhados e cada sujeito atribui sentidos à realidade da qual se apropria (Natividade \& Coutinho, 2012).

Dentre os artigos analisados, cinco utilizaram a perspectiva sócio-histórica nas pesquisas (Diogo \& Maheirie, 2007; Dugnani \& Souza, 2011; Magro \& Coutinho, 2008; Natividade \& Coutinho, 2012; Teixeira, 2009). No estudo de Dugnani e Souza (2011) sobre os sentidos do trabalho para orientadores pedagógicos e sua influência nas práticas desses profissionais, em uma escola pública municipal no interior de São Paulo, foi adotada a compreensão de sentido a partir de Vygotsky (1934/2008), conceituando-o como a somatória dos eventos psicológicos que o termo desperta na própria consciência. Estes eventos são configurados e reconfigurados a partir das experiências do sujeito no ambiente em que se insere. Dessa forma, o sentido conferirá à consciência humana uma dimensão afetiva, além das dimensões cognitivas e intelectuais, de modo que a emoção se revela como unidade indissociável do pensamento e da palavra (Dugnani \& Souza, 2011).

Natividade e Coutinho (2012) investigaram os sentidos do trabalho para crianças de ensino fundamental de uma escola pública, e compreenderam o sentido como uma compreensão mais singular do sujeito, dependente do contexto e do sujeito que o atribui. Cada sujeito pode, então, atribuir sentidos diferentes, em momentos diferentes, a um mesmo fato. Os resultados destacam que as crianças, como atores e autores sociais, são capazes de atribuir sentidos ao trabalho, mesmo que não exerçam nenhuma atividade produtiva, e reiteram a compreensão da produção de sentidos como um processo em constante constituição (Natividade \& Coutinho, 2012).

Além dos estudos citados, outras três pesquisas embasaram seu referencial na perspectiva sócio-histórica em articulação com outras (Coutinho, 2009; Diogo, 2007; Souza \&Moulin, 2014). Dentre elas, Diogo (2007), 
em pesquisa com trabalhadoras assalariadas do setor de limpeza e conservação de uma empresa prestadora de serviços, além de Vygotsky, cita Dejours e explicita a vinculação do sentido do trabalho ao estabelecimento de uma dinâmica de reconhecimento que propicie vivência de satisfação, que equilibraria a relação prazer/desprazer e manteria a mobilização do/a trabalhador/a pró-trabalho. Já o estudo de Souza e Moulin (2014) objetivou refletir sobre os sentidos do trabalho para trinta servidores técnico-administrativos de uma instituição pública federal de ensino e utilizou também a perspectiva existencialista, afirmando que mesmo utilizando diversas matrizes teóricas é possível identificar convergências nas ideias dessas diferentes perspectivas.

\section{Perspectiva construcionista social}

A visão construcionista abrange narrativas e metáforas como formas de discursos, considerando as histórias como desempenhos sociais. A investigação dos sentidos atribuídos a alguma atividade profissional pode, então, ser realizada por meio das narrativas ou discursos produzidos acerca da atividade desenvolvida e de suas vivências, elaborados por meio de múltiplos fatores sociais, econômicos e políticos, nos quais as pessoas são envolvidas (Gergen \& Warhuus, 2001). O sentido pode ser definido como uma construção social, um empreendimento coletivo e interativo, por meio do qual as pessoas, na dinâmica das relações sociais, constroem os termos a partir dos quais compreendem e lidam com as situações e fenômenos a sua volta. A produção de sentidos se dá num contexto em interação, e com atravessamentos por questões de ordem histórica e cultural que permitem a pessoa se relacionar com situações e fenômenos sociais (Spink, 2010; Spink \& Lima, 2013). Nesta abordagem, as pessoas constroem o mundo ao produzir sentidos, utilizando-se de repertórios pessoais e posicionamentos identitários para estes sentidos. A realidade é, então, construída no entendimento de senso comum, cuja compreensão constitui-se em sentidos (Spink, 2010).

Apenas no artigo de Graf e Coutinho (2011) foi adotada a perspectiva construcionista para investigar os sentidos do trabalho para mulheres de um abatedouro avícola. As autoras identificaram as inter-relações entre as pessoas e o trabalho em seus contextos sociais, sem naturalizar os modos de ser, mas contextualizando-os em uma leitura crítica da integração do social com o pessoal. Elas consideraram a constância dos sentidos para quem executa uma atividade laboral, e que pode contemplar aspectos positivos, negativos ou neutros, mas sempre construídos nas tramas do cotidiano (Graf \& Coutinho, 2011).

Em pesquisa de Coutinho (2009) foi adotada uma perspectiva que articula a abordagem construcionista à sócio-histórica, tomando da primeira o lugar de destaque ocupado pela análise do cotidiano e, da segunda, a ênfase na relação dialética entre objetivo e subjetivo. Para a autora, apesar das diferenças, as duas abordagens compartilham a compreensão sobre a indissociabilidade entre sujeito e realidade e entendem que os sentidos são produzidos a partir de experiências concretas das pessoas (Coutinho, 2009).

\section{Perspectiva da psicodinâmica do trabalho}

A psicodinâmica do trabalho, cujo principal representante é Dejours (2015), considera que o trabalho precisa fazer sentido para o sujeito, seus pares e para a sociedade. O sentido do trabalho é, então, formado por dois componentes: o conteúdo significativo em relação ao sujeito e em relação ao objeto. Esses conteúdos significativos permitem a construção da identidade pessoal e social do trabalhador por meio das tarefas que executa, fazendo com que ele consiga se identificar com aquilo que realiza (Dejours, 2015). O sentido do trabalho, nesta abordagem, pode ser conceituado como "uma representação individual e/ou coletiva do ato de trabalhar desenvolvida por meio de um processo de percepção e reprodução do sentido, onde se apreciam as situações vivenciadas no ambiente de trabalho e a representatividade destas para o trabalhador" (Costa, 2013, p. 375). Os elementos para explicação da construção de sentidos do trabalho são três: as características das tarefas realizadas; a organização do trabalho e as diferenças individuais. O sentido dependerá então, do modo como os trabalhadores subjetivam a vivência laboral nas novas formas de organização do trabalho, experienciada por eles nos diversos setores produtivos da sociedade (Dejours, 2011).

Constatou-se que nenhum dos artigos analisados adota a perspectiva da psicodinâmica do trabalho como única para análise dos dados de pesquisa, porém, ela é utilizada em conjunto em quatro estudos para definições de conceitos (Bispo, Dourado, \& Amorim, 2013; Coutinho et al., 2008; Diogo, 2007; Mendes \& Santos, 2013). Na seção que segue, se procurará estabelecer relações entre perspectivas epistemológicas na psicologia, paradigmas sociológicos e eixos paradigmáticos em POT. 


\section{A associação das perspectivas epistemológicas na psicologia e os paradigmas sociológicos e eixos da PTO}

Com base no objetivo de analisar os fundamentos epistemológicos que sustentam as produções científicas nacionais sobre o fenômeno, procederam-se as articulações das perspectivas epistemológicas em psicologia com os paradigmas sociológicos (funcionalismo, interpretativismo, humanismo radical e estruturalismo radical) propostos por Burrell e Morgan (1979). Considerando o funcionalismo, localizado no quadrante da sociologia da regulação e que aborda o sujeito de um ponto de vista objetivista, com pressupostos realistas, positivistas, deterministas e nomotéticos, não é possível afirmar que alguma abordagem esteja localizada exclusivamente neste quadrante. As características dos estudos sugerem algumas aproximações deste paradigma com as investigações na perspectiva cognitivista (Grupo MOW e Lívia Borges). Destaca-se que há pressupostos teóricos da abordagem cognitivista que se alinham ao paradigma interpretativo, o que também ocorre nos estudos com base existencialista de Estelle Morin. Dessa forma, é comum aos artigos que se utilizam destas abordagens o objetivo de reconhecer e/ou interpretar o contexto em que um fenômeno ocorre, com categorias e abordagens à priori e sem propor mudanças no mesmo, conforme os quadrantes relacionados à sociologia da regulação de Burrell e Morgan (1979).

Quando se relacionam os artigos que utilizaram a perspectiva sócio-histórica com os paradigmas de Burrell e Morgan (1979), é possível realizar aproximações com o paradigma interpretativo considerando a tentativa de interpretação do contexto em que o fenômeno ocorre, porém, maiores vinculações podem ser realizadas com o paradigma humanista radical. Isso ocorre ao se considerar que neste paradigma reside uma compreensão do mundo social que tende a ser nominalista, anti-positivista, voluntarista e ideográfica. O que predomina é a visão de sociedade que enfatiza a importância de transcender as limitações dos arranjos sociais existentes, o que é comum aos estudos sobre os sentidos do trabalho que fazem uso dos pressupostos sócio-históricos.

Considerando os pressupostos da psicodinâmica do trabalho é possível relacioná-la aos paradigmas interpretativo e humanista radical, o que também ocorre aos artigos que fazem uso da abordagem construcionista. Estes utilizam de uma lógica subjetiva e, quando consideradas do ponto de vista dos paradigmas de Burrell e Morgan (1979), possibilitam um entendimento acerca do mundo social e permitem reconhecer as mudanças necessárias mediante uma realidade já existente. Em alguns momentos, podem propor mudanças à realidade vigente, mas, em geral, sem uma cisão radical aos modelos estruturais e institucionais já existentes.

Com base nas aproximações realizadas entre as abordagens sobre os sentidos e significados do trabalho e os paradigmas de Burrell e Morgan (1979), percebe-se uma prevalência de perspectivas dos quadrantes mais subjetivos dos paradigmas sociológicos, com algumas abordagens mais relacionadas à sociologia da regulação e outras, com a sociologia da mudança radical, com prevalência desta última na maioria dos artigos analisados neste estudo. Apesar desta prevalência, destaca-se a diversidade teórica e metodológica para o estudo do fenômeno, remetendo à importância dos pesquisadores conhecerem as diferentes bases epistemológicas para estudar o construto e, dessa forma, não incorrerem em possíveis incongruências teóricas, metodológicas e epistemológicas em suas pesquisas.

Especialmente por tratar-se de um fenômeno, que neste estudo analisa-se a partir da PTO, procederamse articulações entre as abordagens teóricas dos artigos investigados com os três eixos temáticos da PTO propostos por Bendassolli et al. (2010): o do comportamento, o da subjetividade e o clínico. O primeiro eixo compreende o comportamento como sinônimo de ação realizada por força do ambiente, parte da observação para extrair suas causas e consequências, e busca a probabilidade de ocorrência dos fenômenos para predizer. Este eixo pode ser representado por pesquisas correlacionais de campo com a operacionalização de construtos, mensuração e controle de variáveis. Por esse motivo, observam-se aproximações deste eixo com os artigos analisados, especialmente na definição metodológica, que privilegiam a perspectiva cognitivista.

O eixo da subjetividade compreende a subjetividade como referente ao sujeito que conhece e é o fundamento do conhecimento. Autores identificados com esta perspectiva utilizam-se de métodos e técnicas que possibilitem analisar amplos conjuntos de significados atribuídos pelo e sobre o sujeito, seu contexto, e sobre a participação do trabalho nos processos de subjetivação. Com forte influência do paradigma crítico, as pesquisas neste eixo buscam subsidiar processos de intervenção e transformação das condições de trabalho, especialmente do ponto de vista do trabalhador e de coletivos de trabalho. Para isso, fazem uso de entrevistas, análise de discursos, histórias de vida etc. Quanto às aproximações, a maior parte das abordagens sobre os 
sentidos e significados do trabalho podem ser identificadas neste eixo, tais como a perspectiva existencialista, construcionista social e sócio-histórica.

O eixo clínico se relaciona às clínicas do trabalho, com características do paradigma clínico, tais como o foco em metodologia qualitativa, o recurso à interpretação e a ênfase na profundidade da compreensão de casos específicos. Neste eixo é estimulada uma ampliação no significado tradicional de clínica (centrada no ser humano), passando a vê-la como recurso de compreensão e transformação de questões de vínculo do sujeito com o trabalho. Dentre as grandes abordagens identificadas neste eixo, cita-se a psicodinâmica do trabalho.

Conforme explicitado por Bendassolli et al. (2010), destaca-se que esta diversidade epistemológica comum a diversos fenômenos estudados pela PTO no Brasil, e também identificada nos estudos dos sentidos e significados do trabalho analisados, é sinal de maturidade da área no âmbito nacional. É necessário ter clareza de que esta diversidade produz um cenário complexo, em que o pesquisador e o profissional de PTO têm a necessidade de confrontar suas atividades com os referenciais que legitimam sua atuação.

O exposto acerca da epistemologia do fenômeno sentidos e significados do trabalho implica que não se trata de escolher entre extremos, entre uma base positivista ou uma clínica, ou entre um paradigma funcionalista ou estruturalista radical, seja considerando os pressupostos de Bendassolli et al. (2010), ou os de Burrell e Morgan (1979), ou adotar posturas "críticas" sectárias e excludentes. Trata-se, propriamente, de compreender o desafio da psicologia e de outras ciências em tratar de fenômenos em constante mutação e procurar por métodos capazes de acessar seus objetos e fenômenos de estudo e que desafiam as intervenções. A produção de conhecimentos sobre as bases epistemológicas de conceitos da PTO suscita a necessidade de se fazer uma análise crítica da produção pelo profissional da área, de modo a qualificar e manter coerência na prática e na pesquisa em PTO.

\section{DISCUSSÃO}

O desenvolvimento de pesquisas sobre o fenômeno psicológicos sentido(s) e significado(s) do trabalho revela a busca pelo aprofundamento de descobertas científicas sobre o assunto. $\mathrm{O}$ aumento da quantidade de estudos sobre este(s) fenômeno(s) confirma que a produção científica está em amplo desenvolvimento, com predominância de artigos na psicologia, principalmente pelas bases de dados pesquisadas. Apesar disso, o(s) sentido(s) e significado(s) do trabalho podem ser apreendidos por diferentes perspectivas, tais como a administração, sociologia e a própria psicologia, sendo que a produção de conhecimento por meio da parceria entre pesquisadores de diferentes ciências e áreas mostra-se enriquecedora e possibilita uma compreensão mais abrangente do fenômeno a partir de diferentes aspectos.

A grande maioria dos estudos foi encontrada na busca pelo termo sentidos do trabalho e, em menor quantidade, do termo significados do trabalho. Isto demonstra a forma como os pesquisadores têm se referido ao fenômeno e ao próprio método de pesquisa utilizado para sua abordagem, visto que os estudos sobre sentido(s) do trabalho fazem uso de métodos predominantemente qualitativos e, a maioria dos estudos sobre os significado(s) do trabalho é realizado por meio de métodos quantitativos. Tal dado, por si só, remete a uma diferenciação teórica e metodológica entre os termos e a coerência epistemológica presente em alguns estudos.

Ressalta-se a prevalência de estudos que utilizam a abordagem existencialista e a abordagem sócio-histórica dentre os artigos analisados. A perspectiva existencialista, a partir de um entendimento do fenômeno de um ponto de vista mais individual e capaz de trazer contribuições gerenciais, concebe os sentidos do trabalho como necessidade vital do ser humano. Nesta abordagem, o ser humano busca dar às suas condutas um sentido que seja aceitável para ele e para sociedade em que vive, mostrando-se como um resultado da atividade humana. Já a perspectiva sócio-histórica refere-se aos significados como produtos históricos de um grupo social, que, no âmbito do sujeito, remetem a um sentido, relacionado com a realidade, com a própria vida e com motivos individuais. Embora essas perspectivas estejam dentre as mais citadas, enquanto embasadoras dos estudos do fenômeno sentido e significado do trabalho destaca-se a crescente utilização da abordagem da psicodinâmica do trabalho, em concomitância com outras perspectivas para a análise de dados.

Mesmo com a diferenciação entre os termos sentidos e significados, verifica-se em alguns artigos certa junção de perspectivas oriundas de diferentes bases epistemológicas. Isto pode indicar uma dificuldade de posicionamento do(s) autor(es) acerca do tema, a necessidade de uma maior apropriação teórico/conceitual do fenômeno ou a necessidade de perspectivas complementares de análises. Esta dificuldade pode também estar relacionada à existência de diversas perspectivas para se referir ao construto, e que possuem abordagens metodológicas 
bastante distintas, indicando a necessidade de se manter uma maior coerência teórica no tratamento e análise dos dados/informações colhidos.

Em relação ao objetivo de identificar aproximações entre as perspectivas teóricas sobre os sentidos e significado na psicologia com os paradigmas sociológicos de Burrell e Morgan (1979), identificou-se uma prevalência de perspectivas alinhadas aos quadrantes subjetivos dos paradigmas, com algumas abordagens relacionadas à sociologia da regulação e outras, predominantes, à sociologia da mudança radical. Quando considerados os eixos propostos por Bendassolli et al. (2010) encontra-se uma prevalência de estudos e perspectivas que se aproximam ao eixo da subjetividade em PTO.

Apesar de tais prevalências, os dados indicam a diversidade presente para a compreensão do fenômeno no ponto de vista de sua epistemologia, remetendo à importância dos pesquisadores contemplarem a existência de diferentes bases epistemológicas para o estudo do construto e, dessa forma, não incorrerem em incongruências teóricas e epistemológicas para a construção de suas pesquisas. Este desafio é recorrente aos fenômenos e objetos estudados pela psicologia e outras ciências humanas e sociais, que são complexos e mutáveis. Para além disso, sugere-se que outros estudos ampliem o olhar sob a epistemologia considerando aspectos ontológicos, metodológicos e de natureza humana, fundamentais para a compreensão da complexidade do fenômeno, e que pouco foram abordados neste artigo.

A produção de conhecimentos referentes a bases epistemológicas de conceitos da PTO, como dos sentidos e significados do trabalho, suscita a uma análise crítica do conhecimento produzido pelo profissional desta área de modo a qualificar e manter coerência no que se refere a prática e a pesquisa no campo do trabalho e das organizações. Nesta pesquisa foi possível revisar considerável conhecimento produzido em âmbito nacional sobre o fenômeno, porém, as informações levantadas indicam as tendências presentes na produção científica nacional em duas importantes bases de dados para a PTO, o que fornece indicativos para novas revisões bibliográficas que contemplem outras bases não acessadas nesse artigo, tais como as internacionais. As limitações deste estudo remetem a essa restrição a bases de dados nacionais, à opção metodológica da não inclusão de anais de congresso como materiais de análises e à não classificação das localidades e instituições às quais os autores dos artigos são vinculados.

Os dados aqui obtidos buscam indicar caminhos para o aprimoramento dos estudos e para futuras produções científicas sobre o assunto, prosseguindo com uma maior delimitação do fenômeno em suas diferentes perspectivas epistemológicas. Uma das principais contribuições desse artigo para a produção do conhecimento está em anunciar futuras possibilidades de estudos sobre o fenômeno em questão. Deste modo, sugere-se a realização de novas revisões sobre as bases epistemológicas que contemplem periódicos internacionais, verificando possíveis diferenças em relação as pesquisas realizadas em outros países, bem como a realização de estudos que possam descrever os métodos de análise utilizados com maior frequência nos estudos sobre sentido(s) e significado(s) do trabalho, dada a diversidade de perspectivas epistemológicas identificadas e que suscitam abordagens metodológicas diferentes ao fenômeno. Também considera-se relevante a realização de estudos que se proponham a identificar as articulações teóricas e empíricas entre os conceitos sentido(s) e significado(s) do trabalho e outros importantes na área de PTO, tais como qualidade de vida no trabalho, cultura organizacional e riscos psicossociais, relações essas que ainda não foram suficientemente estabelecidas na literatura e que potencialmente trariam avanços científicos para a área. Finalmente, com base nas citadas alterações no mundo do trabalho, considera-se relevante prosseguir com os estudos junto a diferentes amostras de trabalhadores de modo a verificar a produção de sentidos em função dos processos de mudanças nas organizações e no trabalho na atualidade para sujeitos diversos.

\section{REFERÊNCIAS}

Aguiar, W. M. J., Liebesny, B., Marchesan, E. C., \& Sanchez, S. G. (2009). Reflexões sobre sentido e significado. In A. M. B. Bock \& M. G. M. Gonçalves (Orgs.), A dimensão subjetiva da realidade: Uma leitura sócio-histórica (pp. 54-72). São Paulo: Cortez.

Antunes, R. (2003). Os sentidos do trabalho: Ensaio sobre a afirmação e negação do trabalho (6a reimp.). São Paulo: Boitempo Editorial.

Baasch, D., \& Laner, A. S. (2011). Os significados do trabalho em unidades de terapia intensiva de dois hospitais brasileiros. Ciência \& Saúde Coletiva, 16(Supl. 1), 1097-1105. doi: 10.1590/S1413-81232011000700041 
Bauman, Z. (2001). Modernidade líquida. Rio de Janeiro: Jorge Zahar Editor.

Bendassolli, P. F. (2009). Psicologia e trabalho: Apropriações e significados. São Paulo: Cengage Learning.

Bendassolli, P. F., \& Borges-Andrade, J. E. (2011). Significado do trabalho nas indústrias criativas. Revista de Administração de Empresas, 51(2), 143-159. doi: 10.1590/S0034-75902011000200003

Bendassolli, P. F., Borges-Andrade, J. E., \& Malvezzi, S. (2010). Paradigmas, eixos temáticos e tensões na PTO no Brasil. Estudos de Psicologia (Natal), 15(3), 281-289. doi: 10.1590/S1413-294X2010000300008

Bendassolli, P. F., Alves, J. S. C., \& Torres, C. C. (2014). Inventário sobre significado do trabalho de profissionais de indústrias criativas. Avaliação Psicológica, 13(2), 177-186.

Bendassolli, P., \& Guedes, S. (2014). Significados, sentidos e função psicológica do trabalho: Discutindo essa tríade conceitual e seus desafios metodológicos. Avances en Psicología Latinoamericana, 32(1), 131-147. doi: dx.doi.org/10.12804/ apl32.1.2014.09

Bendassolli, P. F., \& Borges-Andrade, J. E. (2015). Meaning, meaningfulness, and tensions in artistic work. Revista Psicologia: Organizações e Trabalho, 15(1), 71-81. doi: 10.17652/rpot/2015.1.305

Bispo, D. A., Dourado, D. C. P., \& Amorim, M. F. C. L. (2013). Possibilidades de dar sentido ao trabalho além do difundido pela lógica do mainstream: Um estudo com indivíduos que atuam no âmbito do movimento hip-hop. Organizações \& Sociedade, 20(67), 717-731. doi: 10.1590/S1984-92302013000400007

Bitencourt, B. M., Onuma, F. M. S., Piccinini, V. C., Moreira, L. B., \& Severo, R. B. (2014). Sentidos do trabalho para jovens de um empreendimento solidário e para trainees. Gerais: Revista Interinstitucional de Psicologia, 7(2), 142-155.

Borges, L. O. (1997). Os atributos e a medida do significado do trabalho. Psicologia: Teoria e Pesquisa, 13(2), 211-221.

Borges, L. O. (1998). Os pressupostos dos estudos do significado do trabalho na psicologia social: No caminho do existencialismo. Vivência, 12(2), 87-105.

Borges, L. O., \& Yamamoto, O. H. (2014). Mundo do trabalho: Construção histórica e desafios contemporâneos. In J. C. Zanelli, J. Borges-Andrade \& A. V. B. Bastos (Orgs.), Psicologia, organizações e trabalho no Brasil (2a ed., pp. 25-72). Porto Alegre: Artmed.

Burrell, G., \& Morgan, G. (1979). Sociological paradigms and organizational analysis. Londres: Heinemann Educational Books.

Cavazotte, F. S. C. N., Lemos, A. H. C., \& Viana, M. D. A. (2012). Novas gerações no mercado de trabalho: Expectativas renovadas ou antigos ideais? Cadernos EBAPE.BR, 10(1), 162-180. doi: 10.1590/S1679-39512012000100011

Costa, S. H. B. (2013). Sentido do Trabalho. In F. O. Vieira (Org.), Dicionário crítico de gestão e psicodinâmica do trabalho (pp. 375-380). Curitiba: Juruá.

Coutinho, M. C. (2009). Sentidos do trabalho contemporâneo: As trajetórias identitárias como estratégia de investigação. Cadernos de Psicologia Social do Trabalho, 12(2), 189-202. doi: 10.11606/issn.1981-0490.v12i2p189-202

Coutinho, M. C., Diogo, M. F., \& Joaquim, E. P. (2008). Sentidos do trabalho e saber tácito: Estudo de caso em universidade pública. PSIC, 9(1), 99-108.

Creswell, J. W. (2010). Projeto de pesquisa: Métodos qualitativo, quantitativo e misto (3a ed.). Porto Alegre: Artmed.

Dejours, C. (2011). Psicodinâmica do trabalho: Contribuições da escola dejouriana à analise da relação prazer, sofrimento e trabalho (1a ed., 12a reimp.). São Paulo: Atlas.

Dejours, C. (2015). A loucura do trabalho: Estudo de psicopatologia do trabalho (6a ed.). São Paulo: Cortez - Oboré.

Diogo, M. F. (2007). Os sentidos do trabalho de limpeza e conservação. Psicologia em Estudo, 12(3), 483-492. doi: 10.1590/ S1413-73722007000300005

Diogo, M. F., \& Maheirie, K. (2007). De balde e vassoura na mão: Os sentidos que mulheres serventes de limpeza atribuem aos seus trabalhos. Revista Mal-Estar e Subjetividade, 7(2), 557-579.

Dugnani, L. A. C., \& Souza, V. L. T. (2011). Os sentidos do trabalho para o orientador pedagógico: Contribuições da psicologia escolar. Psicologia da Educação, 33, 29-47.

Flick, U (2013). Introdução à metodologia da pesquisa. Porto Alegre: Penso.

Gergen, K. J., \& Warhuus, L. (2001). Terapia como construção social: Características, reflexões, evoluções. In M. M. Gonçalves \& O. F. Gonçalves (Orgs.), Psicoterapia, discurso e narrativa: A construção conversacional da mudança (pp. 27-64). Coimbra: Quarteto.

Goulart, P. M. (2009). O significado do trabalho: Delimitações teóricas (1955-2006). Cadernos de Psicologia Social do Trabalho, 12(1), 47-55. doi: 10.11606/issn.1981-0490.v12i1p47-55 
Graf, L. P., \& Coutinho, M. C. (2011). Desvelando sentidos no trabalho de mulheres na produção avícola. Aletheia, (35-36), 95-108.

Guba, E. G. (1990). The paradigm dialog. Londres: Sage.

Hackman, J., \& Oldhan, G. (1975). Development of job diagnostic survey. Journal of Applied Psychology, 60(2), 159-170.

Kubo, S. H., \& Gouvêa, M. A. (2012). Análise de fatores associados ao significado do trabalho. Revista de Administração, 47(4), 540-554. doi: 10.5700/rausp1057

Luna, I. N. (2005). Para além das aparências: Construção da identidade no mundo do trabalho. In M. C. P. Lassance, Â. C. Paradiso, M. P. Bardagi, M. Sparta \& S. L. Frishenbruder (Orgs.), Intervenção e compromisso social - Orientação profissional: Teoria e técnica (1a ed., pp. 79-96). São Paulo: Vetor.

Magro, M. L. P. D., \& Coutinho, M. C. (2008). Os sentidos do trabalho para sujeitos inseridos em "empreendimentos solidários". Psicologia em Estudo, 13(4), 703-711. doi: 10.1590/\$1413-73722008000400008

Meaning of Work International Research Team (1987). The meaning of working. Londres: Academic Press.

Mendes, L., \& Santos, F. S. (2013). Os sentidos e significados no trabalho de controlador de tráfego aéreo. Psicologia \& Sociedade, 25(3), 706-717. doi:10.1590/s0102-71822013000300024

Morse, H., \& Weiss, R. (1955). The function and meaning of work and the job. American Sociological Review, 20, 191-198. doi: $10.2307 / 2088325$

Morin, E. M. (2001). Os sentidos do trabalho. Revista de Administração de Empresas, 41(3), 8-19. doi: 10.1590/S003475902001000300002

Morin, E., Tonelli, M. J., \& Pliopas, A. (2007). O trabalho e seus sentidos. Psicologia e Sociedade, 19(Especial), 47-56. doi: $10.1590 / \mathrm{S} 0102-71822007000400008$.

Offe, C. (1989). Trabalho: A categoria-chave da sociologia? Revista Brasileira de Ciências Sociais, 10(4), 5-20.

Natividade, M. R., \& Coutinho, M. C. (2012). O trabalho na sociedade contemporânea: Os sentidos atribuídos pelas crianças. Psicologia \& Sociedade, 24(2), 430-439. doi: 10.1590/S0102-71822012000200021

Padilha, V., \& Grande, M. M. (2011). "A gente fica muito tempo aqui dentro!”: Reflexões sobre o trabalho de gerentes, recepcionistas e camareiras de hotéis. Cadernos de Psicologia Social do Trabalho, 14(1), 111-125. doi: 10.11606/issn.19810490.v14i1p111-125

Ruiz-Quintanilla, S. A., \& Claes, R. (2000). MOW research programs. In J. A. Katz (Ed.), Database for the study of entrepreneurship (pp. 335- 391). New York: JAI/Elsevier Science Inc.

Santos, R. N. M., \& Kobashi, N. Y. (2009). Bibliometria, cientometria, infometria: Conceitos e aplicações. Tendências da Pesquisa Brasileira em Ciência da Informação, 2(1), 155-172.

Sato, L. (2011). Psicologia e trabalho: Focalizando as profissões ignoradas. In B. Medrado \& W. Galindo (Orgs.), Psicologia social e seus movimentos: 30 anos de ABRAPSO (pp. 233-249). Recife: ABRAPSO/Ed. Universitária da UFPE.

Silva, G. C., Kemp, V. H., Carvalho-Freitas, M. N., \& Brighenti, C. R. G. (2015). Significado do trabalho voluntário empresarial. Revista Psicologia: Organizações e Trabalho, 15(2), 157-169. doi: 10.17652/rpot/2015.2.275.

Spink, M. J. (2010). Linguagem e produção de sentidos no cotidiano. Rio de Janeiro: Centro Edelstein de Pesquisas Sociais.

Spink, M. J., \& Lima, H. (2013). Rigor e visibilidade: A explicitação dos passos da interpretação. In M. J. Spink (Org.), Práticas discursivas e produção de sentido no cotidiano: Aproximações teóricas e metodológicas (pp. 71-99). Rio de Janeiro: Centro Edelstein de Pesquisas Sociais.

Souza, S. A. D., \& Moulin, M. G. B. (2014). Serviço público: Significados e sentidos de um trabalho em mutação. Cadernos de Psicologia Social do Trabalho, 17(1), 49-65.

Tausky, C., \& Piedmont, G. E. (1968) The meaning of work and unemployment: Implications for mental health. International Journal of Social Psychiatry, 14, 44-49. doi: 10.1177/002076406801400105

Teixeira, C. M. (2009). As mulheres no mundo do trabalho: Ação das mulheres, no setor fabril, para a ocupação e democratização dos espaços público e privado. Psicologia: Teoria e Pesquisa, 25(2), 237-244. doi: 10.1590/S0102-37722009000200012

Toledo, I. d’Á., Kemp, V. H., \& Machado, M. N. M. (2014). Os sentidos do trabalho para egressos do sistema prisional inseridos no mercado formal de trabalho. Cadernos de Psicologia Social do Trabalho, 17(1), 85-99.

Tolfo, S. R., Coutinho, M. C., Almeida, A. R., Baasch, D., \& Cugnier, J. (2005). Revisitando abordagens sobre sentidos e significados do trabalho. Anais do Fórum CRITEOS. Porto Alegre: Universidade Federal do Rio Grande do Sul. 
Tolfo, S. R., \& Piccinini, V. (2007). Sentidos e significados do trabalho: Explorando conceitos, variáveis e estudos empíricos brasileiros. Psicologia \& Sociedade, 19(Especial), 38-46. doi: 10.1590/S0102-71822007000400007

Tolfo, S. R., Coutinho, M. C., Baasch, D., \& Cugnier, J. C (2011). Sentidos y significados del trabajo: Un análisis con base en diferentes perspectivas teóricas y epistemológicas en Psicología. Universitas Psychología, 10(1), 175-188.

Tolfo, S. R. (2015). Significados e sentidos do trabalho. In P. F. Bendassolli \& J. E. Borges-Andrade (Orgs.), Dicionário de psicologia do trabalho e das organizações (pp. 617-625). São Paulo: Casa do Psicólogo.

Torraco, R. J. (2005). Writing integrative literature reviews: Guidelines and examples. Human Resource Development Review, 4(3), 356-367. doi: 10.1177/1534484305278283

Vygotsky, L. S. (1934/2008). Pensamento e linguagem (J. L. Camargo, Trad.). São Paulo: Martins Fontes.

Zanelli, J. C. (2010). Introdução: Trabalho, saúde e construção da qualidade de vida. In J. C. Zanelli (Coord.), Estresse nas organizações de trabalho (pp. 13-30). Porto Alegre: Artmed. 